\title{
EVOLUCIÓN DE LA PANDEMIA DE COVID-19 EN LOS PRINCIPALES MUNICIPIOS TURÍSTICOS DE MÉXICO
}

\author{
ALFONSO GONZÁLEZ DAMIÁN \\ alfonso.gonzalezdamian@gmail.com \\ Universidad de Quintana Roo, México
}

Con el objetivo de explorar las relaciones entre las características de los municipios turísticos de México y la evolución de la propagación del COVID-19, se realizaron análisis de regresión y clúster bayesianos sobre bases de datos disponibles y de acceso público. Se confirmó que durante las primeras fases de la epidemia las municipalidades con mayor infraestructura y, por lo tanto, con mayor movimiento turístico resultaron en significativo número de casos de contagiados y de fallecimientos; en tanto que, en posteriores etapas, el movimiento turístico perdió relevancia para explicarlos. Se describen las diferencias en la propagación entre clústeres identificados por fase en la evolución de la pandemia. Se incluyen conclusiones, implicaciones y líneas futuras de investigación.

Palabras clave: COVID-19, municipios turísticos de México, propagación epidémica.

\section{EVOLUTION AND IMPLICATIONS OF THE COVID-19 PANDEMIC IN MAIN TOURISM MUNICIPALITIES OF MEXICO}

In order to explore the relationships between the characteristics of Mexico's tourism municipalities and the evolution of the spread of the COVID-19, Bayesian regression and cluster analyzes were carried out on available and publicly accessible databases. It was confirmed that during the first phases of the epidemic, tourism municipalities with greater infrastructure, and therefore with greater tourist movement, resulted in a significative number of cases of infected and deaths, while in later stages, the tourist movement lost relevance to explain them. The differences in the spread between clusters identified by phase in the evolution of the pandemic are described. Conclusions, implications and future lines of research are included.

Keywords: COVID-19, mexican tourism municipalities, epidemic spread. 


\section{Introducción}

E n momentos de incertidumbre es necesario hacer un recuento de los acontecimientos, con el objeto de entenderlos, de manera que existan bases sobre las cuales se puedan visualizar futuros escenarios realistas hacia los que sea viable y deseable avanzar. Tal es el caso del presente documento, que se elabora justamente cuando se encuentra activo el COVID-19 en México, que prácticamente ha llevado a la industria turística al cero; cuando el porvenir es hipotético, tanto para la evolución de la pandemia como para la posible recuperación del turismo.

De tal manera, el objetivo de este trabajo es analizar las relaciones entre las características de los municipios turísticos de México y la evolución de la propagación del COVID-19, con la finalidad de identificar implicaciones relevantes para próximas decisiones en su gestión, ante el embate de nuevos brotes de esta o futuras epidemias que afecten de manera directa al sector.

En el país, los sitios turísticos sufrieron, al igual que el resto de la nación, el impacto de la epidemia. Si bien resultaría prematuro extraer conclusiones respecto a lo que depara a la actividad en torno al turismo en general, en el mundo y en particular para los municipios turísticos de la República Mexicana, es necesario hacer una revisión de lo sucedido, de manera que exista un registro sobre el cual se puedan tomar decisiones, con una mejor comprensión tanto de la propia enfermedad, como del virus que la provoca, de los factores que condicionan su transmisión y la gravedad de sus síntomas, en el ámbito local de los destinos turísticos.

Para alcanzar el objetivo, se diseñó un estudio de carácter exploratorio, retomando información disponible en bases de datos públicas. Evidentemente, no se partió de un diseño más ambicioso, puesto que se hubiera requerido un mayor tiempo para encontrar resultados o la existencia previa de datos adecuados.

En la investigación académica siempre está presente el dilema entre realizar estudios oportunos, relacionados con necesidades actuales, o diseñar estudios de largo plazo que sean sumamente sistemáticos, para arrojar respuestas concluyentes, lo cual se hace patente ante el embate de la pandemia de COVID-19 y sus efectos en el turismo. Este texto da cuenta de ello de manera muy clara: se prefirió actuar con oportunidad para explorar el caso particular de los municipios turísticos de México, a costa de no contar con toda la información necesaria, o en la forma que pudiese 
conducir a aportaciones de tipo concluyente y de amplio alcance, lo cual será materia de otros trabajos.

Hecha esta consideración, el documento comienza con antecedentes sobre la relación entre turismo y epidemias, desde el punto de vista conceptual y a manera de contextualización, así como las decisiones de política pública que se tomaron por el gobierno de México ante el brote de COVID-19. A continuación, se incluyen en el apartado metodológico las variables consideradas para el análisis, las herramientas estadísticas que se aplicaron y se describe el procedimiento seguido para la realización del mismo. Posteriormente, se presenta un apartado de discusión de los resultados, para cerrar con algunas conclusiones e implicaciones que se extraen del estudio efectuado.

\section{Antecedentes}

Desde tiempos remotos, se sabe que las enfermedades se transfieren de una comunidad a otra mediante el contacto entre ellas, ya sea por la interacción entre los individuos, por migración, guerra, comercio o por el intercambio de mercancías, así como de especímenes de flora y fauna que forman parte o que acompañan los intercambios. Las migraciones, como forma principal de los viajes desde tiempos ancestrales, han sido la principal fuente de epidemias a través de la historia (Wilson, 1995); viruela, peste, tuberculosis, influenza, entre otras muchas, que se han extendido a lo largo del tiempo en diversas oleadas y que han cubierto prácticamente toda comunidad en el planeta.

Son múltiples los factores que condicionan el impacto de la migración y de los viajes en general en la transmisión de las enfermedades: la tecnología introducida, los métodos agrícolas y pecuarios, los tratamientos y medicinas, el uso de químicos y pesticidas en regiones que reciben la migración, la deforestación, la construcción de represas, la apertura de carreteras en áreas antes inaccesibles, todo ello se combina para acelerar o disminuir la transmisión de las enfermedades y, por tanto, la aparición de las epidemias (Wilson, 1995).

En la actualidad, el turismo es uno de los principales motivadores de la intensa circulación humana, promueve el contacto entre diversas comunidades y también el intercambio biológico y cultural que, de manera deliberada o no, se produce con tales acercamientos. Particular atención ha recibido en la literatura académica la 
importancia de los viajes aéreos, como detonadores de la aparición y propagación de epidemias y de la transmisión de enfermedades entre comunidades distantes (Driver et al., 1994; Epstein et al., 2007; Grais et al., 2003; Wilson, 2020).

Se sabe que en los sitios en los que existe contacto intensivo entre viajeros y población local, la probabilidad de compartir patógenos entre ambos grupos es alta; entendiendo que en ambos casos posiblemente no se tengan suficientes defensas ante determinados agentes, entonces es incomprensible el que exista una (evidente ahora) limitada relación entre protocolos de contención de epidemias y la industria del turismo, o planes de contingencia específicos por destino turístico, considerando su alta exposición a este tipo de situaciones.

Asimismo, llama la atención el que, más allá de los mencionados estudios sobre la industria aérea y su papel en la transmisión de enfermedades contagiosas, no abunden los estudios que analicen la intensidad de la actividad turística como factor relevante para la propagación de las epidemias, tanto entre visitantes como residentes que entran en contacto con los primeros.

Desde una perspectiva opuesta, sí existe literatura en el ámbito académico enfocada en el impacto que las epidemias tienen en la actividad turística (Bell y Lewis, 2011; Kuo et al., 2008; Mao et al., 2010; Rassy y Smith, 2013; Teitler-Regev et al., 2013; OMT, 2009), con trabajos desarrollados directamente durante la pandemia del COVID-19 (Gössling et al., 2020; Yang et al., 2020).

Llaman la atención en especial las reflexiones sobre lo que habría de hacer la industria turística tras la epidemia actual (Benjamín et al., 2020), aunque no necesariamente se centran en el análisis de lo que sucede en los sitios turísticos durante los períodos críticos, ni tampoco respecto a las variables que confluyen en la evolución de la propagación y desarrollo de una pandemia, que es lo que se pretende explorar en el presente documento.

Existen a su vez otras temáticas en estudios tanto del Caribe como del país, sobre la vinculación entre el turismo y algunas enfermedades infecciosas. Pueden citarse, por ejemplo, el estudio sobre el miedo y el turismo tras la epidemia de influenza $A$ H1N1 de Oehmichen-Bazán y París (2010), el trabajo respecto a la discriminación y homofobia asociadas a la epidemia de VIH (Orozco-Núñez et al., 2015), así como el trabajo en torno a la propagación del virus a través del turismo (George y Richards, 2012). En conjunto, estas investigaciones evidencian el interés por parte de la aca- 
demia en la relación entre el turismo y las enfermedades, su propagación epidémica y los efectos que tienen unos sobre otros.

En el caso de México, se tiene el antecedente de la epidemia de Influenza A H1N1, iniciada el 23 de abril de 2009 y extendida hasta abril de 2010 (Centro Nacional de Programas Preventivos y Control de Enfermedades, Cenaprece, 2012), que fue declarada pandemia por la Organización Mundial de la Salud (OMS) el 11 de junio del 2009. Esto evidenció las deficiencias del sistema de salud en cuanto a prevenir y actuar frente a brotes epidémicos de esta naturaleza (Cejudo, 2020). Como efecto principal de esta epidemia, se lanzó el "Plan nacional para la preparación y respuesta ante la intensificación de la influenza estacional o ante una pandemia de influenza", que de alguna manera es el directo antecedente de la acción del gobierno de México frente al COVID-19, puesto que en ese entonces se declaró que era imposible predecir el comportamiento de los virus estacionales de la influenza, así como lo que ocurriría durante el período pospandémico y, por lo tanto, no habría que bajar la guardia y mantener la vigilancia, dejando la responsabilidad al Comité Nacional para la Seguridad en Salud, de emitir las declaratorias de las fases, de acuerdo con lo establecido por la OMS y las evaluaciones de riesgo realizadas por el sector salud en el país.

La OMS (2009), para efectos de acción frente a nuevos patógenos que tienen el potencial de extenderse por el mundo, ha diseñado un protocolo de actuación que abarca seis fases, las cuales van desde el cero hasta el cinco. Para el caso actual del virus SARS-CoV2, detectado en Wuhan, China, a finales del 2019 (Lu et al., 2020; Paraskevis et al., 2020; Zhang et al., 2020), la OMS declaró la fase uno el 30 de enero de 2020 y con ello informó a los sistemas de salud en los países de la necesidad de prepararse para el impacto de la enfermedad a la que denominó COVID-19.

El 11 de marzo de 2020, se declaró la Fase 3 de la pandemia, con lo que la OMS reconoció que, en muchas regiones, el virus se encontraba totalmente fuera de control y los sistemas de salud rebasados por mucho, con gran número de personas contagiadas, casos con graves síntomas que saturaron hospitales y alto porcentaje de fallecimientos por complicaciones de la enfermedad, tal fue el caso muy temprano y notorio de Italia (Remuzzi y Remuzzi, 2020).

En México, esta situación llevó al gobierno a preparar un protocolo de acción ante el embate de la pandemia, que claramente fue percibida como riesgo, por lo que se instauró el Comité Nacional para la Seguridad en Salud y la participación del Sis- 
tema Nacional de Salud (Cenaprece, 2012), que ha estado a cargo del seguimiento oficial de la enfermedad y de la emisión de recomendaciones tanto para el propio sector salud, como para el gobierno y la ciudadanía en general.

Como portavoz oficial del Comité se nombró al Dr. Hugo López-Gatell, Subsecretario de Prevención y Promoción de la Salud, brindando, a través de informes diarios en los medios de comunicación, datos sobre el avance de la epidemia y las acciones a tomar ante ella. Precisamente, en estas conferencias se presentó el programa de actuación ante los escenarios del COVID-19 en el país, escenarios que, de inmediato y a partir de ese momento, se denominaron "Fases de la epidemia en México".

El primer escenario, "Importación", refiere, como su nombre lo indica, a los casos importados, transmisión de segunda generación y brotes familiares, con un estimado de decenas de casos. El escenario 2, denominado "Dispersión comunitaria", señala transmisión de tercera generación y superior, con brotes comunitarios, con un estimado de cientos de casos. El escenario 3, señalado como "Epidémico", alude a brotes regionales con dispersión nacional y un estimado de miles de casos (López-Gatell, 2020).

Los escenarios/fases que identifican tanto el embate del padecimiento en la población, como las acciones a tomar ante él, tuvieron los siguientes momentos:

a) Fase 1. Inició el 27 de febrero, con el reconocimiento del primer caso confirmado en el país de contagio por SARS-CoV-2; las recomendaciones asociadas fueron: difusión de mensajes preventivos en escuelas y lugares de trabajo.

b) Fase 2. Comenzó el 24 de marzo. Las recomendaciones asociadas a ella fueron evitar el saludo entre personas, la suspensión de eventos en espacios públicos abiertos y cerrados ante brotes regionales, establecimiento de filtro sanitario en escuelas y sitios de trabajo.

c) Fase 3. Arrancó el 21 de abril y las acciones consistieron en mantener la distancia, como en la fase anterior, además de la suspensión de actividades escolares y de actividades económicas en centros laborales con brotes activos, que posteriormente se modificó a la suspensión de toda actividad económica "no esencial". 
Figura 1. Casos confirmados al final de la Fase 3 en municipios turísticos seleccionados de México

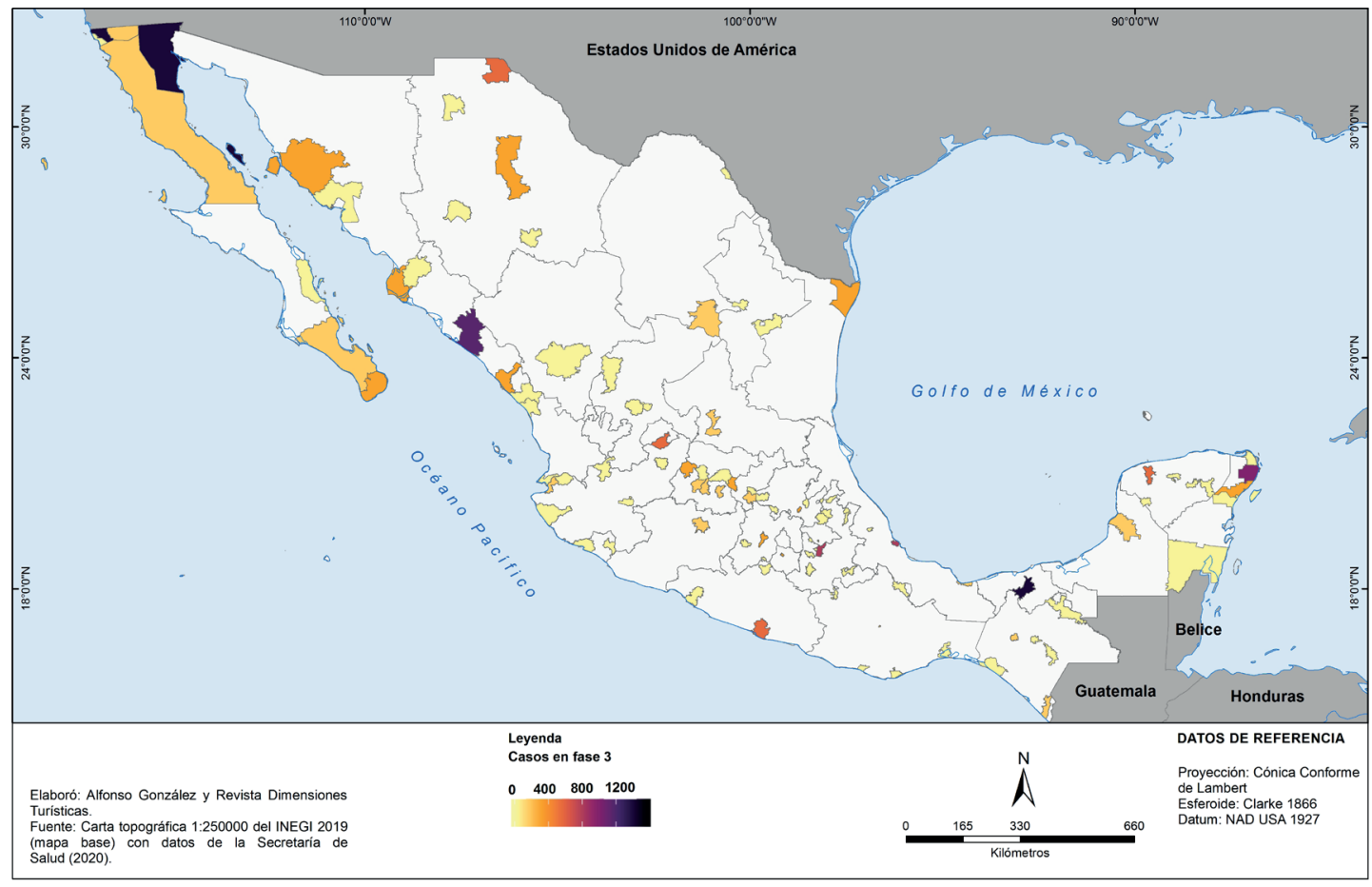

Fuente: Ver interior Figura 1.

Las fases declaradas desde el gobierno federal fueron puestas en práctica por los gobiernos de los 32 estados y, a su vez, en el ámbito local por los gobiernos municipales. La epidemia se vivió de manera diversa a partir de estas declaratorias, en los distintos espacios del país, pero, en términos generales, condujeron la vida cotidiana en todas las poblaciones tanto urbanas como rurales. En la figura 1 se puede ver la ubicación de los municipios que acogen a los centros turísticos en cuestión, destacados de acuerdo con el número de casos confirmados al final de la Fase 3 en el país.

\section{Metodología}

\subsection{Integración de una base de datos consistente}

Cabe señalar que las estadísticas diarias, publicadas por la Secretaría de Salud desde el inicio de la pandemia, se integran considerando las municipalidades como unidad territorial mínima. Dado que se contaba con tal información al día a día, y con el objeto de integrar un conjunto de datos que permitiera describir en términos globales 
lo sucedido durante el desarrollo de la epidemia en México, en los sitios turísticos, se tomó la decisión de analizarlos a escala municipal como demarcación territorial.

No obstante, considerando que no existe en México un listado, ni en la literatura académica un consenso, respecto a qué caracteriza a un municipio turístico, fue necesario integrar una base de datos que permitiera medir, aun cuando fuese indirectamente, la relevancia de la actividad turística en cada localidad elegida, así como identificar sus diferencias sociodemográficas para comprenderlos en contextos particulares.

Con lo anterior en mente, se tomó como punto de partida el listado de los 70 centros turísticos sobre los que la Secretaría de Turismo (Sectur) del país lleva seguimiento, en específico de su actividad hotelera, que es la estadística publicada por la dependencia mencionada a nivel local, dado que las estadísticas generales de llegadas de turistas internacionales se llevan a nivel nacional o estatal y por aeropuerto de arribo, lo que dificulta de alguna manera reconocer de manera numérica las dimensiones e importancia del turismo en estos espacios.

De la relación de 70 centros turísticos, se consideró el más reciente como referencia para filtrar la información de la pandemia, correspondiente al 2018, que muestra la situación de la actividad hotelera en más de 100 destinos en México, esto a pesar del título del listado que alude a solo 70 (Sectur, 2020). Este conjunto fue ubicado en su demarcación municipal, lo que permitió elegir a aquellos que para este documento se han considerado como municipios turísticos ${ }^{1}$. Con ello, se integró una serie de 107 zonas, del cual se omitieron las tres ciudades más grandes del país, México, Monterrey y Guadalajara.

Una vez identificados, se conformó la base de datos a partir de la publicada por la Secretaría de Salud (2020) sobre la pandemia, de la que se extrajo la información relativa a los municipios previamente catalogados como turísticos.

En cuanto a los datos que se consideraron, se incorporaron los casos diarios confirmados oficialmente de COVID-19 y las defunciones registradas por el padecimiento cada día, por municipio turístico, acumulados en tres cortes temporales, para lo

\footnotetext{
1 Evidentemente se trata de una solución "no elegante", pues existen municipios que alojan a más de uno de los centros turísticos. Hay centros turísticos cuya zona metropolitana se extiende a través de límites entre municipalidades. Además, hay algunos con muy poca población, algunos muy poblados que, al no aparecer en el listado, quedaron fuera del análisis. Sin embargo, la decisión tomada permitió realizar un análisis consistente, al menos en el marco de este trabajo exploratorio.
} 
cual se optó por utilizar los números acumulados por etapa, aunque en múltiples trabajos (Ridenhour et al., 2018) se prefieran las tasas de contagio, la velocidad de crecimiento diario o la tasa de letalidad.

Los tres cortes temporales se establecen como sigue: a) el inicio de la etapa de "Casos importados", 27 de febrero; b) el inicio de la etapa de "Contagio comunitario", 24 de marzo; y c) el inicio de la etapa "Epidemia", 21 de abril. Se consideró como fecha final de la Fase 3 al 18 de mayo, en la que el gobierno declaró el inicio de la recuperación (Diario Oficial de la Federación de México, 2020).

A esta información sobre casos confirmados y fallecimientos diarios por municipio, se agregaron dos conjuntos de variables que estaban disponibles de manera pública, para describir por una parte "lo turístico" del municipio y, por otra, sus características sociodemográficas².

\subsubsection{Variables turísticas}

Las variables consideradas para caracterizar los municipios turísticos fueron elegidas en conjunto. Con el objeto de contar con información que pudiese alimentar el análisis, no se le asignó una ponderación o prevalencia a alguna sobre las otras, pues la intención fue que el propio estudio, mediante las herramientas elegidas para ello, permitiera elegir las que mostraran relevancia. Si bien pudieron tomarse otras variables, y lo deseable en términos técnicos hubiese sido diseñar un experimento en el cual se recogieran los datos sobre variables previamente elegidas, el enfoque fue el opuesto; es decir, a partir de la información disponible, elegir aquella que pudiera ser de utilidad. En tal sentido se incluyeron las siguientes variables sobre el tema turístico:

a) El número de cuartos de hotel disponibles en el municipio turístico. Variable seleccionada como un indicador de la capacidad del destino para recibir turistas y, por lo tanto, un indicador del movimiento potencial de visitantes a los municipios estudiados (Sectur, 2020).

b) Contar con aeropuerto o no. Al respecto cabe señalar que diversos aeropuertos en el país, aunque llevan el nombre de una ciudad aledaña, no necesaria-

\footnotetext{
2 Nuevamente, se optó por preferir la información disponible, aunque no fuera la más actual, considerando que existiera para todos los municipios turísticos seleccionados. Cabe señalar que la mejor variable en el ámbito turístico hubiera sido el número de llegadas internacionales, por ser la preferida en los estudios sobre turismo, no obstante, precisamente esa variable no existe actualizada, diaria ni a nivel municipal en México.
} 
mente se encuentran territorialmente dentro de los límites del mismo municipio; sin embargo, para fines analíticos y de consistencia se tomó la decisión de contabilizar como municipio con aeropuerto por la cercanía, aunque este se encontrara fuera de él, cuando la población urbana era precisamente la incluida originalmente en el listado de los centros turísticos de la Sectur. El contar con aeropuerto puede confirmar de alguna manera el movimiento de visitantes hacia/desde las municipalidades.

c) Contar con puerto marítimo. Respecto a este punto, sucede algo similar a los aeropuertos, por lo que la decisión tomada para integrar la información fue homóloga. El contar con puerto marítimo puede confirmar, en conjunto con tener aeropuerto y la infraestructura hotelera, el movimiento potencial de visitantes hacia/desde los municipios turísticos.

d) El tipo y subtipo de destino turístico. Clasificado por la propia Sectur: de playa, Centros Integralmente Planeados (CIP), tradicionales y otros destinos de playa, de ciudad (del interior y fronterizas) y otros (poblaciones y ciudades no incluidas en ninguna de las anteriores categorías). Se eliminó el subtipo "Ciudades grandes" que solo incorporaba las tres omitidas del análisis, como se mencionó antes (Sectur, 2020).

Estas variables, si bien no proceden de una categorización con rigor científico, sí obedecen a una lógica de funcionamiento del sitio turístico, desde el punto de vista gubernamental, que a lo largo de los años ha conducido la toma de decisiones a nivel central. Ejemplo de ello es que un CIP de playa es gestionado en su zona turística por el Fondo Nacional de Fomento al Turismo (Fonatur), en tanto que las llamadas playas tradicionales son gestionadas única y exclusivamente por las administraciones locales. El incluirlas en el presente documento permite también hacer una aproximación, hasta cierto punto, a la forma en la que se organiza la gestión de lo turístico a nivel municipal, lo cual también sucede con la última variable:

e) El ser considerado como Pueblo Mágico. Pondera si en el territorio municipal se ubica el centro turístico reconocido como tal por el gobierno del país, a finales de 2019 (Sectur, 2019). Esta variable permite identificar una forma particular de gestión del turismo a nivel local, muy próxima a la gobernanza comunitaria, en la que participan en las decisiones los actores locales, por arriba de las decisiones del gobierno municipal y del estatal. 
Por tanto, la elección de este conjunto de variables sigue un criterio principalmente práctico pues, como se ha mencionado, no se pretendía sino realizar una primera exploración sobre sus relaciones (de las variables) con las sociodemográficas y particularmente con la evolución de la epidemia en el ámbito de los municipios turísticos de México.

\subsubsection{Variables sociodemográficas}

Las características sociodemográficas de una municipalidad pueden también ser identificadas a partir de muchas y diversas variables, en función del objetivo del análisis. Para efectos de este documento se eligieron algunas de ellas consideradas (de manera empírica si bien fundamentada en los estudios revisados en la literatura académica) como factores de la propagación de las epidemias en general y en particular para la de COVID-19:

a) El número de habitantes. La población total de cada municipio en el año 2019 (Conapo, 2018). Un mayor número de habitantes también corresponderá de manera directa con un mayor número de contagiados y de fallecimientos en una epidemia.

b) La densidad de población del municipio. Dato que se obtuvo del año 2015 (INEGI). En el caso de la propagación del COVID-19, la cercanía física de las personas en el ámbito urbano genera más probabilidad de contagio (OMS, 2020), por lo que aquellos municipios con un gran número de poblaciones urbanas tendrán también una mayor densidad y, siguiendo la misma lógica, un mayor número de contagiados y fallecidos.

c) El número promedio de ocupantes por vivienda para el año 2015 (INEGI). De manera homóloga a la variable anterior, la proximidad que se tiene dentro de las viviendas entre personas conduce a una alta probabilidad de contagio.

d) El total de población ocupada en el municipio para el año 2015 (INEGI). El contar con un empleo formal, también de manera indirecta, conduce a una cercanía con otras personas y, por ende, a una significativa probabilidad de contagio.

e) El grado promedio de escolaridad en el municipio para el año 2015 (INEGI). La escolaridad da una referencia del acceso a información que pueda ser re- 
levante para mejorar las condiciones de protección y seguridad, así como de prevención ante una epidemia.

f) Población sin afiliación a servicios de salud en el municipio para el año 2015 (INEGI). De manera similar a la anterior, el no contar con servicios de salud puede ser relevante para que las personas no obtengan información relativa a protegerse y prevenir contagios.

g) Densidad de camas hospitalarias por cada 10 mil habitantes en el municipio para el año 2018 (Secretaría de Salud, 2020). Da una visión de la capacidad de atención a enfermos por parte del sistema de salud en el territorio municipal.

\subsection{Análisis realizados a los datos}

Con esta base de datos se realizó un primer análisis con enfoque exploratorio, con el objeto de identificar y seleccionar aquellas variables que resultan más explicativas del número acumulado de casos para cada una de las cuatro etapas identificadas (Antes de la Fase 1 o Fase previa, Fase 1, Fase 2 y Fase 3). Se utilizó un promediado bayesiano de modelos de regresión basado en BIC (Gibbons et al., 2008) a través una exploración del espacio de modelos posibles, con simulación Markov Chain Monte Carlo (MCMC), mediante el paquete BAS (Clyde, 2020) del software de programación para análisis estadístico R (R Core Team, 2020).

La aplicación de este análisis, como en otros trabajos (Raftery, 1995; Wasserman, 2000), permitió identificar aquellas variables que tienen una mayor probabilidad de quedar incluidas en la generación de un modelo de regresión. Para efectos del presente trabajo, se eligieron las variables que obtuvieron una probabilidad calculada entre todos los modelos, mayor a 1/3:

a) Para la Fase previa: el tratarse de una ciudad del interior (0.34) fue la única variable explicativa, con baja probabilidad de ser incluida. En esta etapa no hubo casos confirmados oficiales, aunque muchos fueron considerados como sospechosos o no hubo ocasión de confirmar su diagnóstico (Secretaría de Salud, 2020).

b) Para la Fase 1: la población del municipio (0.91), el número de cuartos disponibles (0.98), el tratarse de un destino de playa tradicional (0.47) y el índice de envejecimiento de la población (0.35). La siguiente variable con mayor probabilidad fue la población no afiliada a servicios de salud con 0.22 . 
c) Para la Fase 2: el tratarse de un destino fronterizo (0.98), la población no afiliada a los servicios de salud (0.99), el número de habitantes (0.49) el número de cuartos disponibles (0.4) y el número promedio de personas por vivienda (0.44). La siguiente variable con mayor probabilidad fue el que se tratara de un destino de playa tradicional con 0.18 .

d) Para la Fase 3: la población no afiliada a servicios de salud (0.99), el tratarse de un destino fronterizo (0.99), el número promedio de ocupantes de una vivienda (0.74) y la densidad poblacional del municipio (0.37). La siguiente variable con mayor probabilidad fue el número de cuartos disponibles con 0.24.

A continuación, se aplicó un segundo análisis con la finalidad de identificar grupos entre los destinos turísticos, con base en las variables obtenidas en el análisis anterior, para cada una de las etapas de la pandemia. Se aplicó el análisis clúster bayesiano, específicamente con modelado de mezcla finita gaussiana, ajustado por algoritmo EM, mediante el paquete mclust (Scrucca et al., 2016) el cual permitió identificar conjuntos de destinos turísticos con características distintas entre sí, pero comunes dentro de cada grupo para cada uno de los cortes temporales.

Para el caso de la etapa previa a la pandemia, el modelo obtenido fue Ell (esférico, igual volumen) con tres componentes. En el caso de la Fase 1 el modelo obtenido fue EEE (elipsoidal, volumen, forma y orientación iguales) con cinco componentes. Para la Fase 2, el modelo fue VEV (elipsoidal, forma igual) con dos componentes, y para la Fase 3 el modelo resultante fue EEV (elipsoidal, forma y volumen iguales) con dos componentes.

Enseguida, se muestran los resultados, los clústeres obtenidos y sus características.

\section{Resultados}

\subsection{La epidemia en los municipios turísticos antes de ser declarada como tal}

Durante la etapa previa a la declaratoria formal de la epidemia en México, los destinos se agrupan en tres clústeres, modelados a partir de la variable "ciudad del interior". En la tabla 1 se muestra la estadística descriptiva de dichos clústeres.

En esta Fase previa, se puede observar que se presentaron casos sospechosos y algunos por diagnosticar de COVID-19, aun cuando el gobierno no declaraba oficial- 
mente la epidemia. Esto debido a que muchos casos, que posteriormente fueron confirmados como COVID-19, no se habían detectado o se tenían contabilizados únicamente como pendientes de determinación.

Tabla 1. Estadística descriptiva de los clústeres para el período previo a la fase 1 de la epidemia

\begin{tabular}{|c|c|c|c|}
\hline Variable & Clúster 1 & Clúster 2 & Clúster 3 \\
\hline CSA & 22 & 422 & 22 \\
\hline CCA & 0 & 2 & 0 \\
\hline CC $(\bar{x}, s)$ & $0(0)$ & $0.5(0.58)$ & $0(0)$ \\
\hline FA & 0 & 2 & 0 \\
\hline $\mathbf{F}(\overline{\mathrm{x}}, \mathrm{s})$ & $0(0)$ & $0.5(0.58)$ & $0(0)$ \\
\hline $\mathbf{H}(\overline{\mathrm{x}}, \mathrm{s})$ & 227412 (329 288.6) & 589798.8 (276 953.8) & 516109.5 (442 118.6) \\
\hline DP $(\bar{x}, s)$ & $334.71(597.84)$ & $1028.32(522.49)$ & 759.85 (983.18) \\
\hline OV $(\bar{x}, s)$ & $3.65(0.27)$ & $3.82(0.26)$ & $3.73(0.24)$ \\
\hline IE $(\overline{\mathrm{x}}, \mathrm{s})$ & $25.44(9.48)$ & $23.25(4.8)$ & $25.96(6.98)$ \\
\hline $\operatorname{NASS}(\bar{x}, s)$ & $37308.83(57609.83)$ & 93635.5 (28 307.88) & 81287.61 (78 115.33) \\
\hline $\mathrm{CD}(\overline{\mathrm{x}}, \mathrm{s})$ & 40957.96 (84 903.34) & $\begin{array}{r}35714(16 \\
867.83)\end{array}$ & 37366.82 (26 294.79) \\
\hline$A(p)$ & 0.34 & 0.25 & 0.67 \\
\hline $\mathbf{P M}(p)$ & 0.23 & 0 & 0.03 \\
\hline $\mathbf{S}$ & $\begin{array}{r}\text { Otros } 46 \\
\text { Playa } 7 \\
\text { Playa T. } 7 \\
\text { Fronterizas } 5 \\
\text { CIP } 5 \\
\text { Total } 70\end{array}$ & Del Interior 4 & Del Interior 33 \\
\hline
\end{tabular}

$\begin{array}{ll}\text { CSA: } & \text { Casos sospechosos acumulados } \\ \text { CCA: } & \text { Casos confirmados acumulados } \\ \text { CC: } & \text { Casos confirmados } \\ \text { FA: } & \text { Fallecidos acumulados } \\ \text { F: } & \text { Fallecidos } \\ \text { H: } & \text { Habitantes } \\ \text { DP: } & \text { Densidad de población } \\ \text { OV: } & \text { Ocupantes por vivienda }\end{array}$

$\begin{array}{ll}\text { IE: } & \text { Índice de envejecimiento } \\ \text { NASS: } & \text { No afiliados a servicios de salud } \\ \text { CD: } & \text { Cuartos disponibles } \\ \text { A: } & \text { Aeropuerto } \\ \text { PM: } & \text { Puerto marítimo } \\ \text { S: } & \text { Subtipo de destino turístico (frecuencia y total } \\ & \text { por clúster) } \\ (\bar{x}, \mathrm{~s}): & \text { Media, desviación estándar } \\ (p): & \text { Proporción }\end{array}$

Fuente: Elaboración propia con base en datos de la Sectur (2019 y 2020), la Secretaría de Salud (2020) y el INEGI (2015).

Como se observa en la tabla 1, el segundo de los clústeres generados incluye municipios turísticos con los únicos casos tanto confirmados como fallecidos. En relación con las características descriptivas de los clústeres, se puede afirmar que es notable una diferencia importante en el número de habitantes promedio para las municipalidades, siendo el clúster 2 el que los agrupa, así como también en el pro- 
medio de habitantes no afiliados a servicios de salud. Los municipios turísticos que tuvieron casos fueron Aguascalientes y Pachuca, en tanto que los que presentaron fallecimientos fueron Celaya e Irapuato; el resto de los sitios no presentó casos confirmados de COVID-19 ni fallecimientos en esta fase.

Cabe señalar que, en esta etapa previa a la pandemia, la comparación entre clústeres no arroja mucha información respecto a su evolución, por lo que se incluyó aquí principalmente con la intención de utilizarla como punto de referencia para observar lo sucedido en las fases subsecuentes.

\subsection{La primera fase de la epidemia en los municipios turísticos de México}

Durante la primera fase, considerada como aquella en la que se presentan solo casos denominados "importados" y cuando se da por iniciada la presencia de la epidemia en el país, la mayoría de los casos confirmados se diagnosticaron en personas que recientemente viajaron al extranjero, a sitios en los que ya se encontraba activo el padecimiento. En esta etapa se agruparon en cinco clústeres, modelados a partir de las variables: habitantes del municipio, número de cuartos disponibles, ser del tipo de "playa tradicional" y el índice de envejecimiento de la población. La condición turística (intensidad de la actividad e infraestructura para ello) es de clara relevancia en esta etapa.

Es notable que los clústeres dos y cuatro (ver figura 2 y tabla 2), presentan una importante diferencia, con relación a los demás, respecto a los casos confirmados y fallecimientos. En la tabla 2 se puede observar que, a diferencia de lo obtenido en la fase anterior, aquí sí hay discrepancias importantes en las medias de cuartos disponibles y en la población residente en los municipios turísticos.

El clúster 4 tiene el mayor promedio de habitantes en los municipios turísticos agrupados en él, pero no el mayor promedio de cuartos disponibles, el cual está en el clúster 2 y ambos son los que presentan el mayor promedio de casos confirmados. A su vez, el clúster 3 presenta el menor promedio tanto en cuartos como en habitantes, e igualmente menor promedio de casos confirmados. 
Figura 2. Casos confirmados y fallecidos por clúster, para la Fase 1 de la epidemia

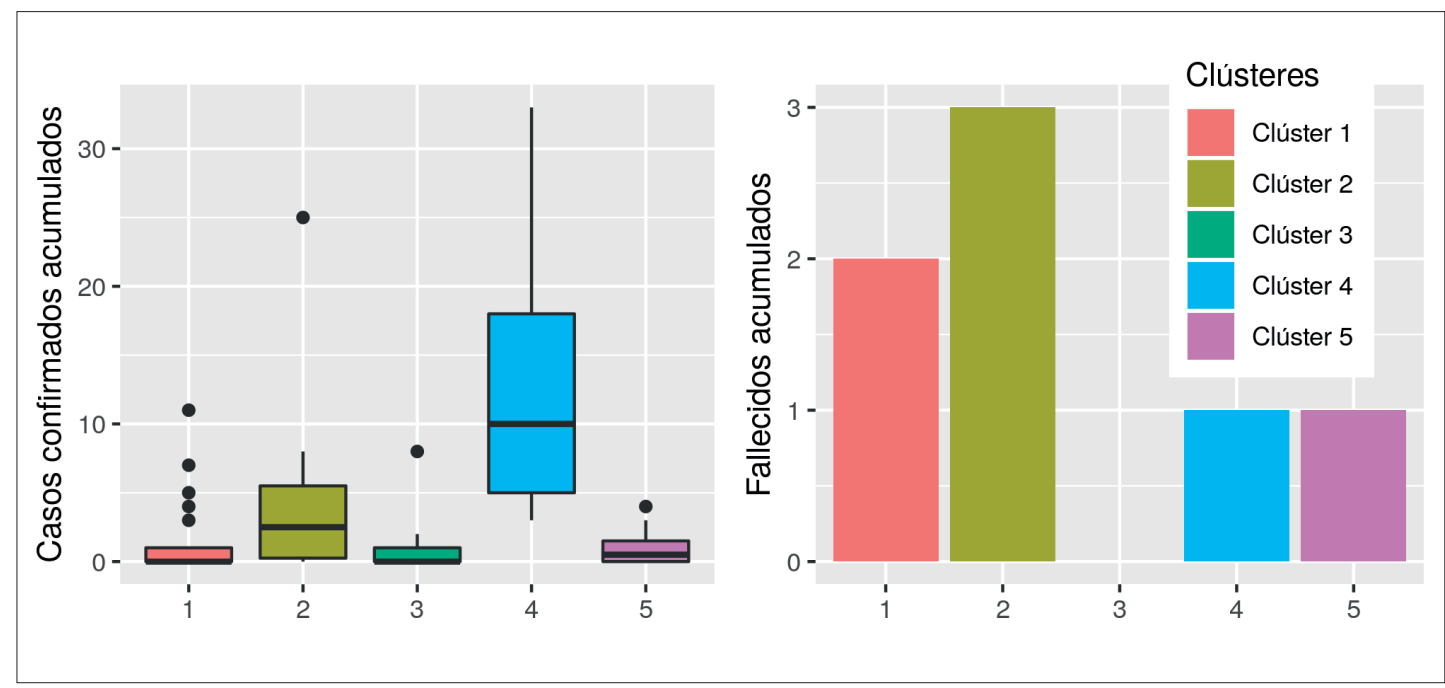

Fuente: Elaboración propia con base en datos de la Sectur (2019 y 2020), la Secretaría de Salud (2020) y el INEGI (2015).

Para el clúster 1, los municipios turísticos representativos en esta primera etapa, tomando los tres con mayor número de casos confirmados de COVID-19, son: San Andrés Cholula (11), Los Cabos (7) y San Pedro Cholula (5). Otras 16 municipalidades de este clúster no presentaron casos confirmados en la Fase 1.

En el clúster 2 fueron: Cancún (25), Acapulco (8) y Riviera Maya (6), en tanto que no presentaron casos confirmados tres municipalidades, para la primera fase de la epidemia. En el clúster 3, con mayor número de casos fueron Pachuca (8), Campeche, Los Mochis, Salamanca y Costa Alegre, todos con dos casos. Este clúster tuvo 27 municipios sin casos confirmados de COVID-19 durante la primera fase. En cuanto al clúster 4, aquellos con mayor número de casos fueron: Mérida (33), San Luis Potosí (22), y Puebla (20). Tres municipalidades presentaron el menor número de casos en este clúster (3): Chihuahua, Culiacán y Hermosillo. 
Tabla 2. Estadística descriptiva de los grupos al final de la Fase 1 de la epidemia

\begin{tabular}{|c|c|c|c|c|c|}
\hline Variable & Clúster 1 & Clúster 2 & Clúster 3 & Clúster 4 & Clúster 5 \\
\hline CCA & 39 & 49 & 26 & 196 & 9 \\
\hline $\mathrm{CC}(\overline{\mathrm{x}}, \mathrm{s})$ & $1.3(2.47)$ & $4.9(7.56)$ & $0.61(1.34)$ & $11.53(8.35)$ & $1.12(1.55)$ \\
\hline FA & 2 & 3 & 0 & 1 & 1 \\
\hline $\mathbf{F}(\bar{x}, s)$ & $0.07(0.25)$ & $0.3(0.95)$ & $0(0)$ & $0.06(0.24)$ & $0.12(0.35)$ \\
\hline $\mathbf{H}(\overline{\mathrm{x}}, \mathrm{s})$ & $181.32(171.33)$ & $446.38(261.02)$ & $139.46(132.45)$ & $1,072.07(342.68)$ & $165.42(147.58)$ \\
\hline DP $(\bar{x}, s)$ & $409.3(597.71)$ & 491.78 (737.06) & 340.38 (696.37) & 777.09 (796.97) & $989.36(1,300.39)$ \\
\hline OV $(\bar{x}, s)$ & $3.79(0.28)$ & $3.44(0.22)$ & $3.73(0.23)$ & $3.64(0.21)$ & $3.47(0.19)$ \\
\hline IE $(\bar{x}, s)$ & $18.82(3.76)$ & $21.48(8.48)$ & $27.98(3.86)$ & $23.74(5.62)$ & $46.58(6.74)$ \\
\hline NASS $(\bar{x}, s)$ & 31.65 (32.94) & $81.68(57.1)$ & 20.39 (23.59) & $165.75(79.32)$ & $28.5(27.1)$ \\
\hline $\operatorname{CD}(\bar{x}, s)$ & $32.89(46.51)$ & $167.6(160.63)$ & $10.15(9.57)$ & $56.1(2.36)$ & $24.63(26.97)$ \\
\hline$A(p)$ & 0.37 & 0.8 & 0.19 & 0.94 & 0.5 \\
\hline $\mathbf{P M}(p)$ & 0.17 & 0.9 & 0.07 & 0 & 0 \\
\hline $\mathbf{S}$ & $\begin{array}{r}\text { CIP } 3 \\
\text { Del Interior } 9 \\
\text { Otros } 11 \\
\text { Playa } 5 \\
\text { Fronterizas } 2 \\
\text { Total } 30\end{array}$ & $\begin{array}{r}\text { CIP } 1 \\
\text { Del Interior } 1 \\
\text { Playa } 1 \\
\text { Playa T. } 7 \\
\text { Total } 10\end{array}$ & $\begin{array}{r}\text { CIP } 1 \\
\text { Del Interior } 12 \\
\text { Otros } 28 \\
\text { Playa } 1 \\
\text { Total } 42\end{array}$ & $\begin{array}{r}\text { Del Interior } 13 \\
\text { Otros } 1 \\
\text { Fronterizas } 3 \\
\text { Total } 17\end{array}$ & $\begin{array}{r}\text { Del Interior } 2 \\
\text { Otros } 6\end{array}$ \\
\hline
\end{tabular}

CCA : Casos confirmados acumulados

CC: $\quad$ Casos confirmados

FA: $\quad$ Fallecidos acumulados

F: $\quad$ Fallecidos

$\mathrm{H}: \quad$ Habitantes (miles de personas)

DP: Densidad de población

OV: Ocupantes por vivienda

IE: Índice de envejecimiento
NASS: No afiliados a servicios de salud (miles de personas)

CD: $\quad$ Cuartos disponibles (miles de cuartos)

A: $\quad$ Aeropuerto

PM: $\quad$ Puerto marítimo

S: $\quad$ Subtipo de destino turístico (frecuencia y total por clúster)

$(\bar{x}, \mathrm{~s})$ : Media, desviación estándar

(p): $\quad$ Proporción

Fuente: Elaboración propia con base en datos de la Sectur (2019 y 2020), la Secretaría de Salud (2020) y el INEGI (2015).

Del clúster 5, los más altos fueron: Cuernavaca (4), Oaxaca (3), Colima y Tampico ( 1 cada uno), en tanto que cuatro espacios turísticos no presentaron casos confirmados por COVID-19 en la Fase 1 para este clúster.

\subsection{La segunda fase de la epidemia en los municipios turísticos de México}

Durante la Fase 2, en la que se presentan contagios a nivel comunitario, los destinos se agrupan ahora en dos clústeres, modelados considerando las variables: número de habitantes no afiliados a servicios de salud, tamaño de la población, promedio de habitantes por vivienda y número de cuartos. Al igual que en la fase anterior, siguen teniendo importancia explicativa del número de casos y de fallecimientos las variables de la actividad turística, aunque en mucha menor medida que otros 
aspectos sociodemográficos de las poblaciones. Esto indica, de alguna manera, que las variables turísticas perdieron relevancia en comparación con la Fase 1 de la pandemia. Si bien la actividad turística en esta fase aún representa un factor para el número de casos confirmados de COVID-19.

Figura 3. Casos confirmados y fallecidos por clúster, para la Fase 2 de la epidemia

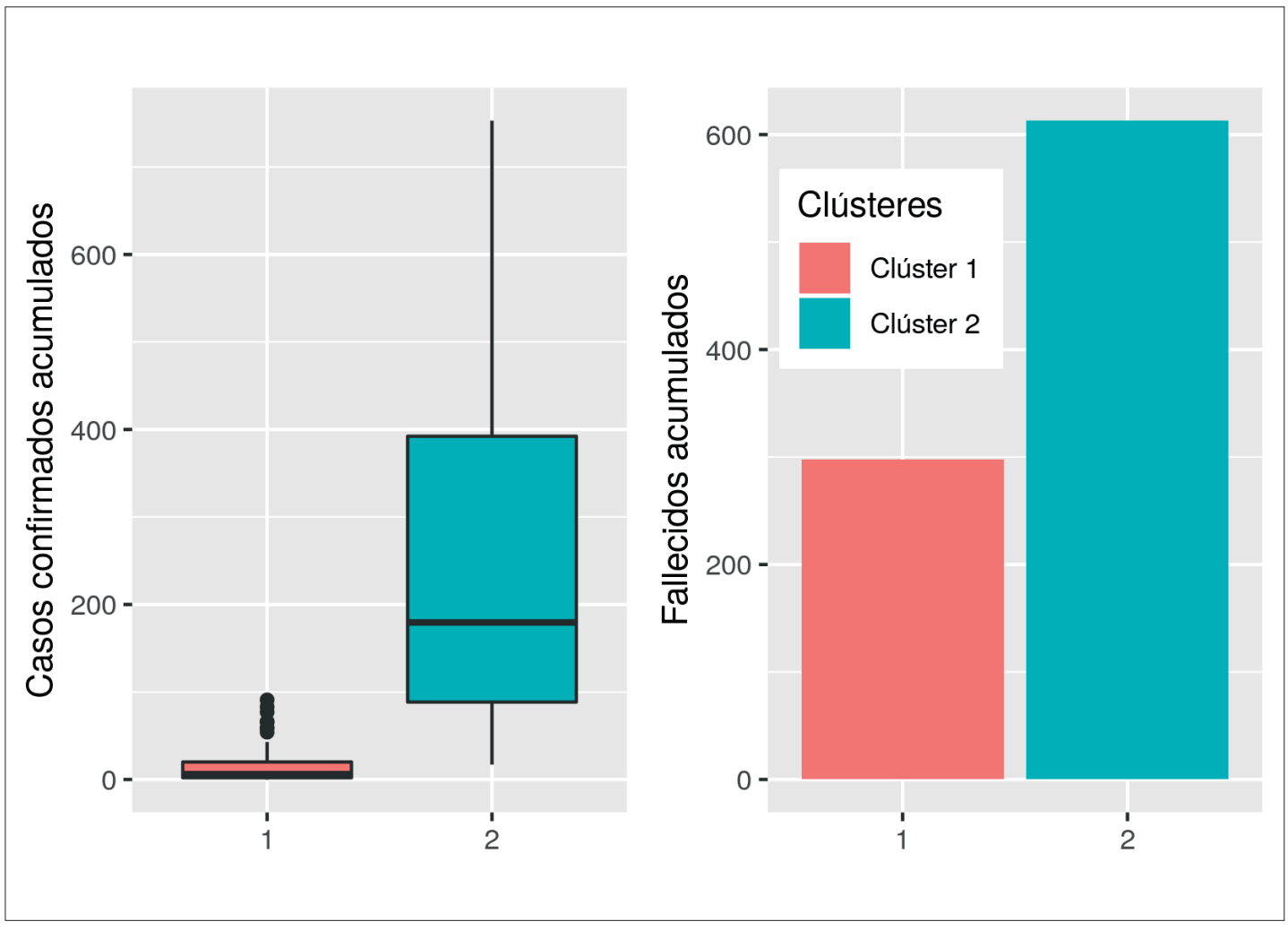

Fuente: Elaboración propia con base en datos de la Sectur (2019 y 2020), la Secretaría de Salud (2020) y el INEGI (2015).

Como puede observarse en la figura 3 y en la tabla 3, el clúster 2 presentó tanto una alta cantidad de casos confirmados como el mayor número de fallecidos en promedio, y es también el que tiene mayor cantidad de habitantes, el mayor número de personas no afiliadas a servicios de salud y el mayor número de cuartos disponibles. Por su parte, en el clúster 1 quedaron las municipalidades con menor número de casos, de habitantes y de cuartos disponibles, así como de personas no afiliadas a los servicios de salud. 
Municipios turísticos representativos para los clústeres de esta fase son aquellos de mayor número de casos confirmados. Para el clúster 1: La Paz (91), Querétaro (83) y Los Mochis (77); en tanto que 13 municipalidades no tuvieron casos confirmados en la Fase 2 de la epidemia en este clúster. Para el clúster 2, se encuentran Tijuana (753), Mexicali (494) y Culiacán (468), en tanto que el centro turístico con menor número de casos en este clúster fue Piedras Negras (17).

Tabla 3. Estadística descriptiva de los grupos al final de la Fase 2 de la epidemia

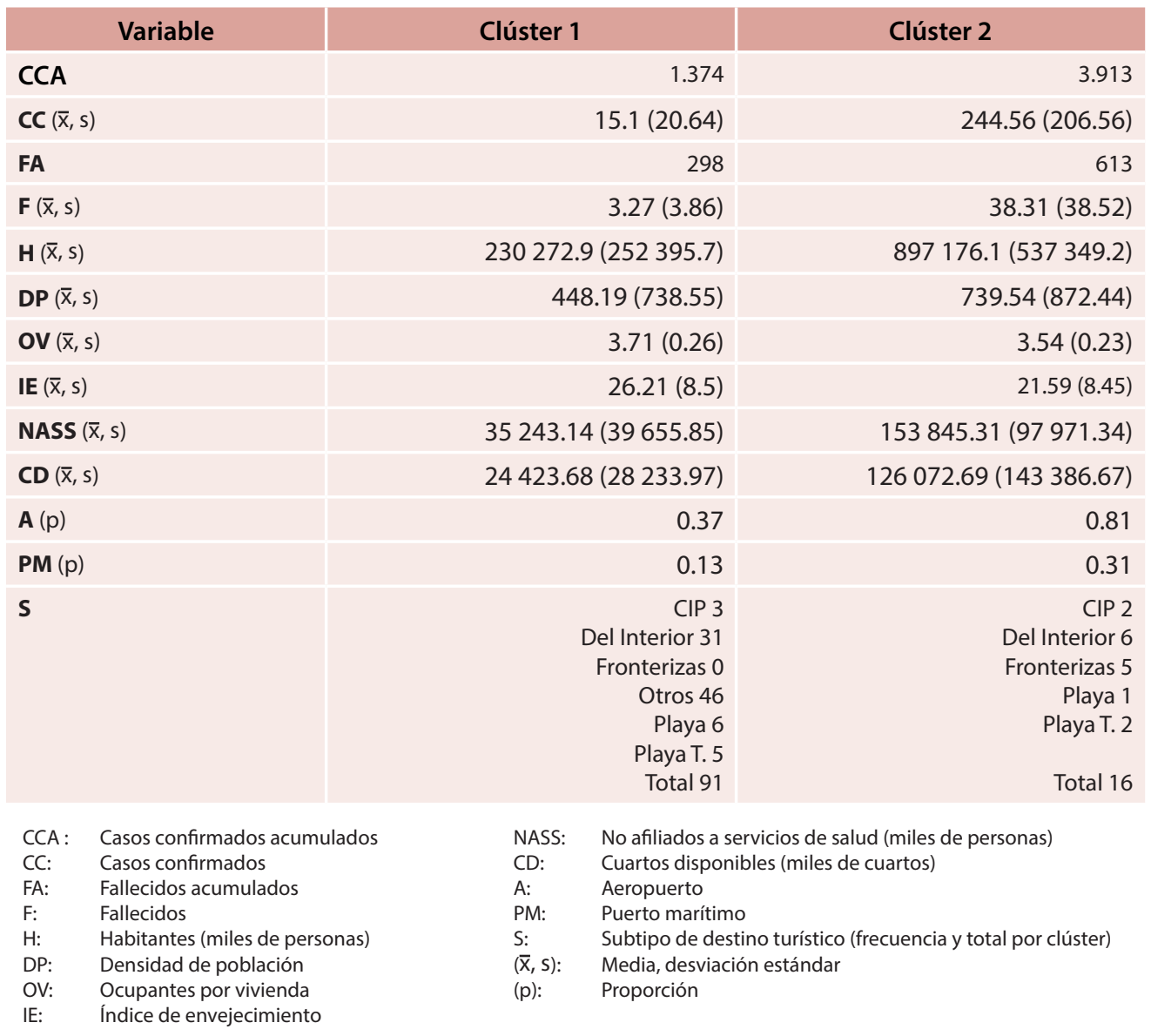

Fuente: Elaboración propia con base en datos de la Sectur (2019 y 2020), la Secretaría de Salud (2020) y el INEGI (2015).

\subsection{La tercera fase de la epidemia en los municipios turísticos de México}

Para la tercera fase, considerada de transmisión epidémica a nivel nacional, los destinos se agrupan en dos clústeres nuevamente modelados a partir de las variables: población no afiliada a servicios de salud, el tratarse de un destino fronterizo, el promedio de habitantes por vivienda y la densidad de población del municipio. 
Como puede observarse en la figura 4 y en la tabla 4, atrae la atención que en el segundo clúster quedaron integrados los territorios turísticos con mayor número de casos confirmados de COVID-19, pero en el clúster 1 se encuentran aquellos con mayor número de fallecidos.

Figura 4. Casos confirmados y fallecidos por clúster, para la Fase 3 de la epidemia

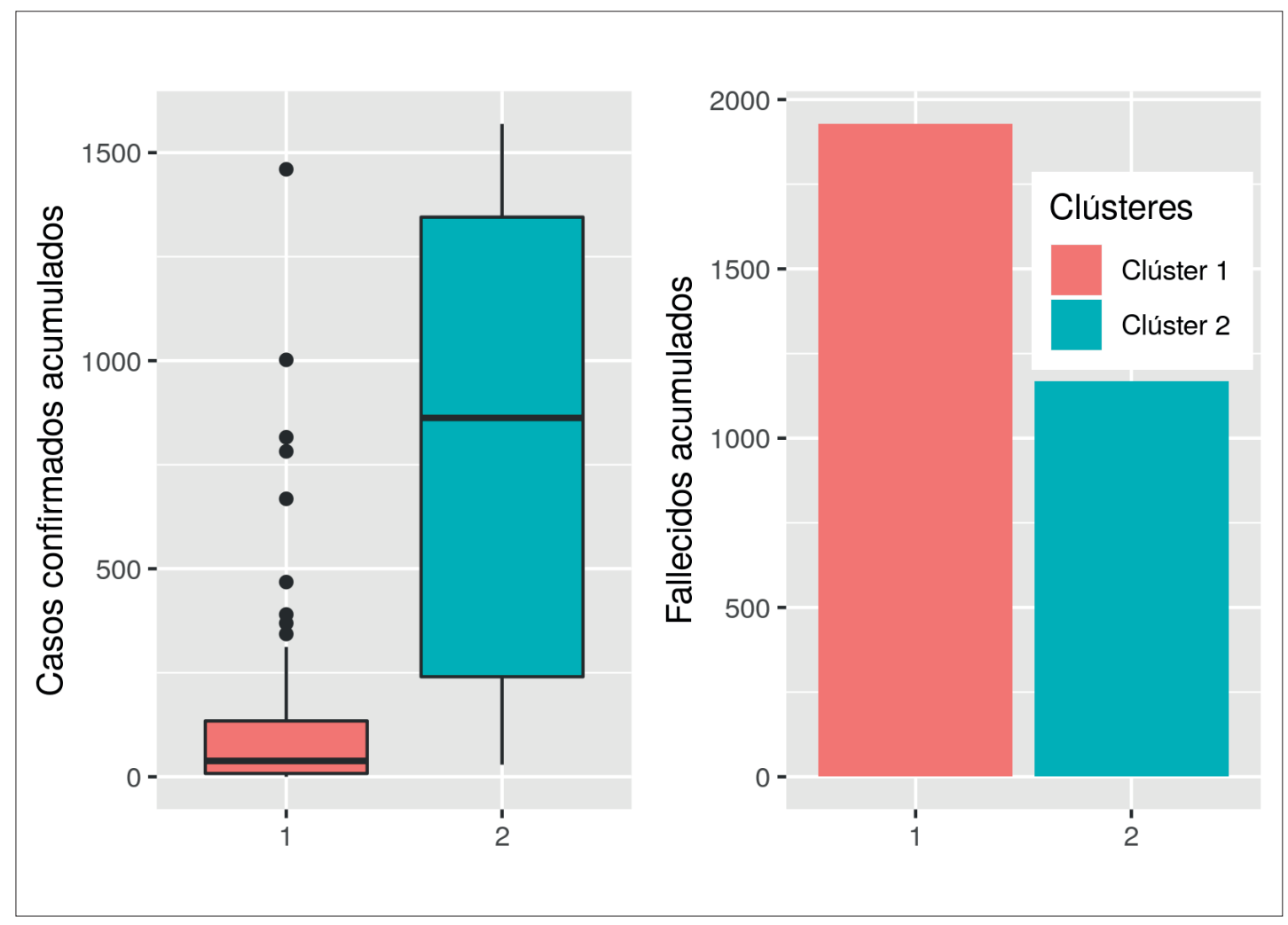

Fuente: Elaboración propia con base en datos de la Sectur (2019 y 2020), la Secretaría de Salud (2020) y el INEGI (2015).

El segundo clúster tiene municipios con mayor número de habitantes y el mayor número de personas no afiliadas a los servicios de salud, la mayor parte de ellos cuentan con aeropuerto; en tanto que el clúster 1 agrupa a centros turísticos con mayor número de cuartos disponibles y también presentó el mayor número de casos confirmados acumulados, aunque el promedio es menor que para el segundo clúster, en el cual se encuentran todos los fronterizos y uno del interior.

Municipios turísticos representativos para el clúster 1 fueron: Villahermosa (1460), Cancún (mil dos) y Puebla (816), los centros con mayor número de casos confir- 
mados, mientras que hubo cuatro municipalidades sin casos confirmados de COVID-19 para la Fase 3. En cuanto al clúster 2 fueron: Tijuana (mil 569), Mexicali (mil 407) y Culiacán (mil 159), cuyo municipio con menos casos fue Piedras Negras (29).

Tabla 4. Estadística descriptiva de los grupos al final de la Fase 3 de la epidemia

\begin{tabular}{|c|c|c|}
\hline Variable & Clúster 1 & Clúster 2 \\
\hline CCA & 12.387 & 4.862 \\
\hline $\mathrm{CC}(\bar{x}, \mathrm{~s})$ & 122.64 (225.19) & $810.33(660.83)$ \\
\hline FA & 1.928 & 1.168 \\
\hline$F(\bar{x}, s)$ & $19.09(36.65)$ & $194.67(199)$ \\
\hline$H(\bar{x}, s)$ & 294832.5 (341 472) & 921928 (667 690.2) \\
\hline $\mathrm{DP}(\bar{x}, \mathrm{~s})$ & $498.03(777.29)$ & $386.13(484.6)$ \\
\hline OV $(\bar{x}, s)$ & $3.7(0.27)$ & $3.52(0.12)$ \\
\hline IE $(\bar{x}, s)$ & $25.85(8.72)$ & $20.03(3.42)$ \\
\hline $\operatorname{NASS}(\bar{x}, s)$ & 47320.79 (58 506.6) & 148208.5 (124 072.6) \\
\hline $\mathrm{CD}(\bar{x}, \mathrm{~s})$ & 40005.43 (71 956.27) & $\begin{array}{r}33195(23 \\
266.18)\end{array}$ \\
\hline$A(p)$ & 0.42 & 0.67 \\
\hline$P M(p)$ & 0.17 & 0 \\
\hline S & $\begin{array}{r}\text { Del Interior } 36 \\
\text { CIP } 5 \\
\text { Otros } 46 \\
\text { Playa } 7 \\
\text { Playa T. } 7 \\
\text { Total } 101\end{array}$ & $\begin{array}{l}\text { Del Interior } 1 \\
\text { Fronterizas } 5\end{array}$ \\
\hline
\end{tabular}

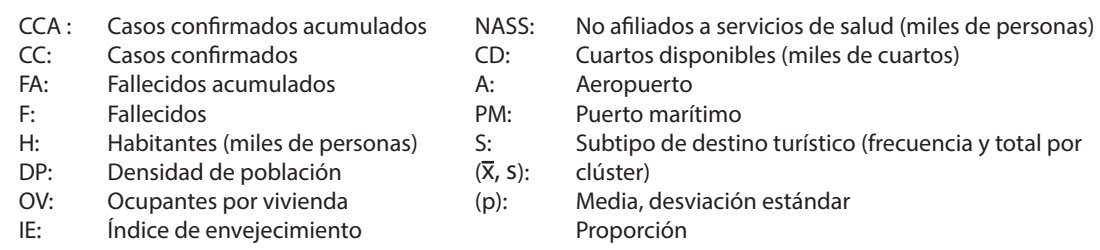

Fuente: Elaboración propia con base en datos de la Sectur (2019 y 2020), la Secretaría de Salud (2020) y el INEGI (2015).

\section{Discusión}

Los resultados presentados confirmaron lo que se esperaba que caracterizara la propagación de la epidemia en los municipios turísticos de México: el contagio del padecimiento resulta más probable al inicio, en la llamada Fase 1, en sitios con mayor intensidad de actividad turística, en los que, además del tamaño de la pobla- 
ción, la variable número de cuartos influye de manera importante en la explicación de la cantidad de casos confirmados y de fallecimientos.

En la Fase 2, cuando se esperaba ya un contagio comunitario, la variable número de cuartos sigue siendo relevante, pero, como mostró el análisis, con una menor probabilidad de ser incluida como variable explicativa que en la Fase 1, en tanto que comienza a notarse que juegan un rol principal otras variables, características de las poblaciones, sean o no turísticas.

De manera muy clara, en la Fase 3 el número de cuartos ya no es una variable que tenga un rol explicativo, lo que se puede interpretar como una confirmación de que la presencia de la actividad turística en las ciudades, ya no fue tan relevante, como sí lo fue el tratarse de un centro turístico fronterizo, con mayor número de habitantes no afiliados a centros de salud, y la densidad de la población, como variables explicativas del número de casos y fallecidos; no obstante, también es verdad que durante esta etapa la actividad turística, el movimiento y traslado de personas, prácticamente se detuvo en el país por la denominada "Jornada de sana distancia", que llevó a la mayor parte de la población a confinarse en sus domicilios y al cierre de la mayoría de los negocios y centros de trabajo.

En este sentido, era de esperarse que se encontrara este resultado para la Fase 3, así como el hecho de que el contagio aumentara entre menores, con las condiciones de la denominada "sana distancia" en contexto, tales como el número alto de habitantes en las viviendas y la densidad de la población.

Pero, en realidad, ¿qué significa que, en la fase inicial de la epidemia, los municipios turísticos con mayor intensidad de contacto entre visitantes (dado que ofrecen una mayor capacidad de recibirles y son poblaciones con mayor número de habitantes), hayan resultado en mayor número de casos confirmados? Si bien el título en México de esta etapa "Casos importados", da una idea de la razón de que esto sea así, también evidencia que, a pesar de los controles y cuidados que se tuvieron en el seguimiento a casos confirmados, atendiendo a las recomendaciones de la OMS (2020), el contacto entre viajeros y población local de manera intensa posibilita la transmisión del patógeno, sin ser detectado en realidad.

Lo anterior se confirma en los resultados mostrados aquí, específicamente en los clústeres de la primera etapa, en los que municipios turísticos con baja o mediana población, o con baja o media capacidad de recibir turistas (cuartos disponibles) tu- 
vieron también un menor número de casos confirmados de COVID-19. En la figura 5 se ilustran las ocho municipalidades que alojan a los destinos turísticos con mayor número de contagiados durante la Fase 1 de la epidemia.

Figura 5. Los ocho municipios turísticos con mayor número de casos en la Fase 1 (clúster 4)

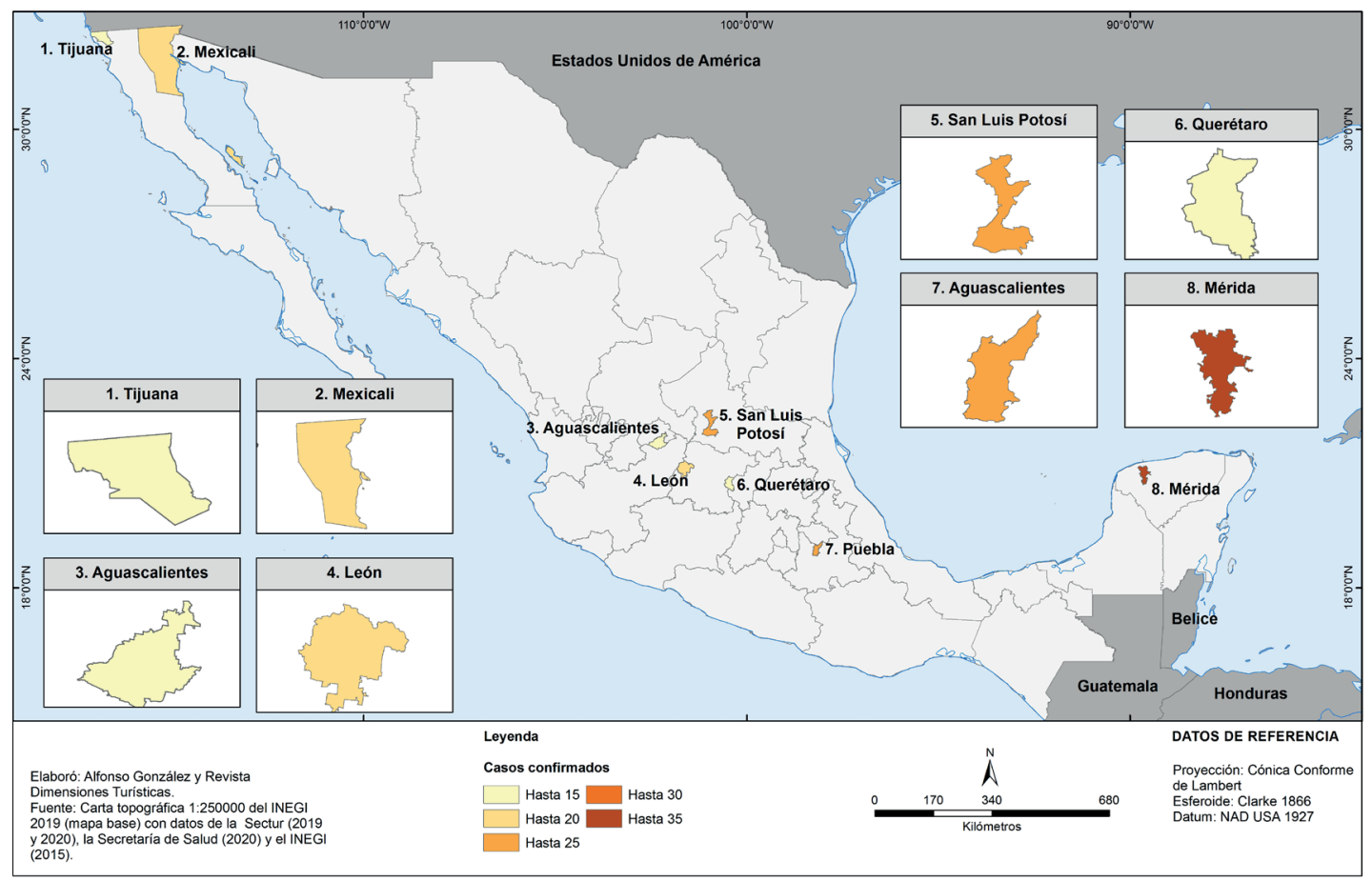

Fuente: Ver interior Figura 5.

El hecho de que al pasar a la Fase 2 de la epidemia, si bien la variable de cuartos disponibles siguió apareciendo en el resultado del análisis como explicativa de los casos confirmados y fallecidos por COVID-19 en los municipios turísticos, esto ya no tuvo el mismo peso que en la primera fase, siendo, por otra parte, el tamaño de la población en el territorio municipal la que tuvo primordial impacto.

En la figura 6 se observa a los ocho municipios que acogen los centros turísticos con mayor número de casos confirmados durante la Fase 2 de la epidemia. Cabe señalar que además del cambio en el orden de aparición, también deja de aparecer en este grupo Querétaro y en su lugar se incorpora Villahermosa.

Diversas variables no resultaron explicativas del número de casos confirmados y de fallecidos por COVID-19 en los municipios turísticos de México, para ninguna de las 
fases de la epidemia, tal fue el caso de contar con aeropuerto o puerto marítimo, la escolaridad, el número de camas de hospital disponibles. De hecho, solo apareció el índice de envejecimiento en la etapa previa a la epidemia que, con tan pocos casos, no puede considerarse en realidad alguna explicación al respecto.

Figura 6. Los ocho municipios turísticos con mayor número de casos en la Fase 2 (clúster 2)

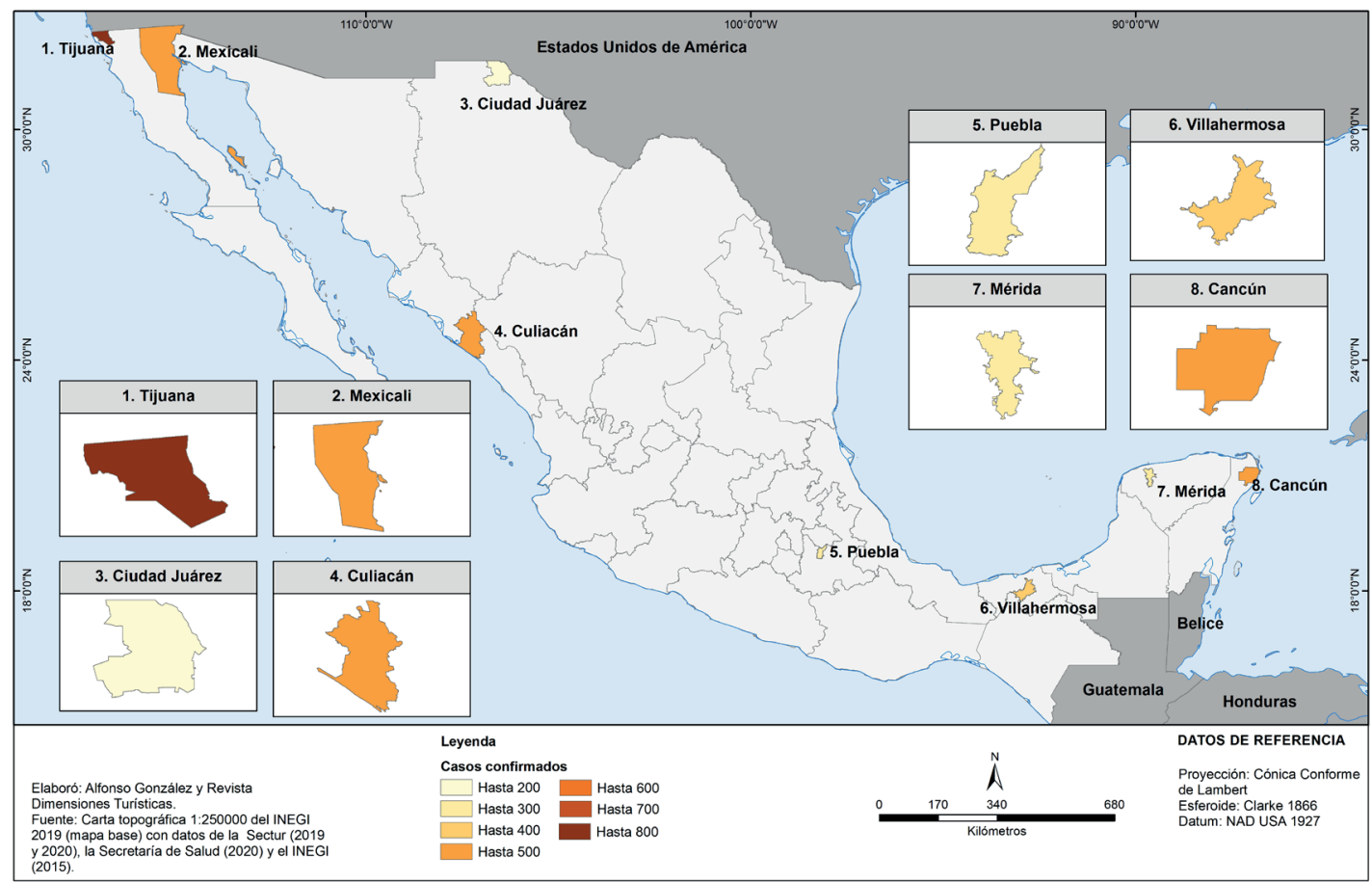

Fuente: Ver interior Figura 6.

En el presente análisis se ha hecho énfasis en las relaciones entre datos, que evidencian relaciones objetivas entre variables; sin embargo, no se hizo reflexión respecto a la parte subjetiva que, sin duda, acompaña a toda epidemia, y la de COVID-19 no es excepción; en el sentido de que, en muchos sitios en el país, la enfermedad y la salud son alusiones sociales relacionadas con cierta forma de comprender el mundo, y como tal, guían el comportamiento de la gente de manera consistente, de forma interna a la representación, aunque esta se contraponga con la información oficial y la científica, proveniente de datos objetivos (Bavel et al., 2020).

Esta parte de la realidad, sin duda, no puede ser negada; no obstante, no forma parte del presente análisis, aunque se sabe que en diversos municipios del país ni la actividad turística se detuvo por completo, ni se respetó el distanciamiento social, 
no se siguieron las recomendaciones de las autoridades de salud y del gobierno en general, por lo que, sin que se tenga un registro formal de ello, el flujo de visitantes y la actividad turística, si bien limitada hasta cierto punto, se mantuvo a lo largo de las tres fases de la epidemia y ello, seguramente, introduce un sesgo que en este momento es imposible de medir, sobre los datos analizados aquí.

\section{Conclusiones}

En el presente texto se realizó un recorrido por las fases de la epidemia de COVID-19 en los municipios turísticos de México. Mediante la aplicación de herramientas de análisis estadístico de corte bayesiano, se elaboraron modelos explicativos del número de casos confirmados y fallecidos en las referidas etapas, y se agruparon (por clústeres) las municipalidades con base en las variables que resultaron significativamente explicativas en cada una de ellas.

La primera fase, denominada de "importación", que inició en México con la identificación formal del primer caso de contagio por el virus SARS-CoV-2 el 27 de febrero de 2020, señaló como variables explicativas a la población que habita el municipio donde se ubica el centro turístico y el número de cuartos de hotel disponibles (usada como indicador de la fortaleza de la infraestructura para el turismo en el centro turístico), con importancia y peso similar en la agrupación en clústeres.

Para la segunda fase, que dio inicio el 24 de marzo, en la que el gobierno de México reconoció que el brote de COVID-19 ya no era solo a consecuencia de contagios contraídos por viajeros al extranjero, o por contacto directo o indirecto con este tipo de individuos, se mantuvo presente como variable el número de cuartos disponibles; sin embargo, tomaron mayor fuerza otras que caracterizan a las poblaciones sean o no turísticas; ahora los cuartos de hotel disponibles tuvieron un menor peso e importancia en la agrupación en clústeres.

Para la tercera fase, que dio inicio el 21 de abril y que concluyó, por formalidad enfocada en la planificación del gobierno de México, el 18 de mayo, las variables que mejor explican el número de casos confirmados y fallecimientos por COVID-19 son las que hacen referencia, por una parte, a la mayor proximidad entre personas, tales como el promedio de habitantes por vivienda y la densidad de población, y por otra, el no estar afiliado a servicios de salud, que muy probablemente indique 
también cierto desconocimiento (o desconfianza) respecto a lo que el sector salud recomendaba hacer y no hacer durante la fase de contagio más intensa.

Interpretada esta información en conjunto conduce a concluir que, durante las etapas previas a la declaratoria de la pandemia y durante sus primeras fases, el contacto e interacción entre visitantes y habitantes locales tuvo un peso relevante en la transmisión de la enfermedad, al menos para el caso de los municipios turísticos de México. Este hallazgo, confirma lo que tanto la literatura académica como la teoría, e incluso el sentido común, indican respecto a la forma en la que ingresa una epidemia en un territorio en el que antes no se padecía.

Ello resulta también la principal aportación del análisis, puesto que se destaca que las variables con mayor capacidad explicativa no fueron la presencia de aeropuertos o puertos marítimos y, notablemente, tampoco el tamaño de la población, sino la fortaleza de la infraestructura para el turismo, los cuartos de hotel disponibles, lo que involucra no solo a los viajeros, sino a la actividad turística completa, como factor para la propagación de la epidemia, en el caso de COVID-19. Algo que muy probablemente resultaría igual condicionante para el caso de presentarse otros brotes epidémicos en el futuro.

Implicar a la industria turística no es un asunto menor, si se considera que, hasta ahora, solo se involucró a la industria del transporte (aéreo principalmente, pero también al náutico), en la necesidad de adoptar medidas preventivas y de vigilancia epidemiológica en las etapas interpandémicas. Se apela entonces a la reflexión de que este sector tendría que participar en el futuro, de una manera mucho más directa y contundente, en la prevención y vigilancia de estos temas de salud pública, en conjunto con otros actores de la industria, tanto en acciones como en compromiso financiero.

El estudio realizado se fundamenta en las bases de datos oficiales, las cuales, como sucede generalmente, no gozan de la aceptación general y son señaladas en muchos casos de no representar la verdad completa e incluso, en ocasiones, de ocultarla de manera deliberada. Esta situación, tanto si fuera o no cierta, escapa de las posibilidades del presente trabajo; no obstante, incluso con las posibles limitaciones reales, o no, que pueda tener la información, es la que se encuentra accesible y que puede ser útil para la toma de decisiones en el futuro, por lo que puede ser considerada como una aproximación válida de lo verdaderamente sucedido en las municipalidades, durante el primer brote de la epidemia de COVID-19. 
Esta limitación, sin embargo, lleva también a la reflexión de la necesidad de realizar futuros estudios en la misma línea de tipo descriptivo, apoyándose en datos complementarios, suplementarios o convergentes, que permitan triangular los resultados aquí presentados.

Ante ello, la principal restricción de este trabajo es que se basa en la información disponible al momento en el que se realizó, lo que evidencia la necesidad de efectuar nuevos análisis, en los que se consideren fuentes diversas de datos, tratamientos previos a ellos; por ejemplo, el cálculo de tasas de contagio o de reproducción de la enfermedad, en lugar del número de contagiados, o la densidad poblacional del municipio por localidad en las principales ciudades incluidas en ellos, en lugar del solo dato de la densidad municipal, así como otras variables que reflejen de mejor manera el movimiento turístico en los sitios analizados.

Del mismo modo, como ya se indicaba en el apartado de discusión, es necesario confrontar los datos con la representación social, a nivel local, de la enfermedad, la epidemia y las medidas recomendadas y tomadas por el gobierno y las autoridades locales, a la par de las instrucciones de los científicos y de la OMS, de manera que se comprenda no solo el comportamiento numérico de la epidemia, sino su significado y evolución a nivel comunitario, desde la enorme diversidad de cosmovisiones diferenciables a lo largo y ancho del territorio mexicano, así como para los distintos estratos y ámbitos socioculturales en un país marcado por la desigualdad.

Es de destacar el hecho de que, como aquí se mostró, durante las fases previas y también en las primeras fases de propagación de la epidemia, la interacción entre visitantes y residentes locales, incentivada por la actividad turística, jugó un papel de relevancia, lo que tiene implicaciones prácticas que habrán de ser tomadas en cuenta por la industria afín en general y por los destinos turísticos en específico.

No es suficiente que la responsabilidad por mantener medidas de higiene y seguridad, así como una permanente vigilancia epidemiológica atenta a los comunicados de la OMS, esté a cargo únicamente de las autoridades de salud. Es necesario que la industria turística se involucre, que conozca la problemática, adopte prácticas de prevención y de cuidados recomendables e, idealmente, se corresponsabilice, en acciones financieras, en las medidas preventivas durante las denominadas fases interpandémicas, así como de control sanitario en la fase epidémica, con lo que ello implique en términos de productividad y rentabilidad. La salud y la vida humana tendrían que estar por encima de otros intereses. 
Evidentemente, también es de relevancia señalar que, esta corresponsabilidad reforzada en las etapas previas deja de ser de central importancia en fases posteriores, aún para los propios destinos turísticos. Esto permite hacer notar que las industrias tanto turística como de los viajes, los destinos en general, aún con lo dicho en el párrafo anterior, no requerirían tomar medidas de prevención exhaustiva de manera permanente, sino como reacción rápida ante los avisos de la OMS. Dicho en otras palabras, la corresponsabilidad debería ser permanente de ahora en adelante, las acciones directas habrán de tomarse en rápida reacción a los futuros avisos de oleadas de la actual o de próximas pandemias.

Mención adicional merece el hecho de que resulta necesario encontrar mecanismos para que la población se afilie o acerque a los servicios de salud, tanto públicos como privados, así como encontrar vías para disminuir el número de habitantes por vivienda, indicadores ambos de carencias económicas y sociales, que se evidencian incluso en un estudio centrado solo en municipios turísticos.

\section{Referencias}

Bavel, J. J. V., Baicker, K., Boggio, P. S., Capraro, V., Cichocka, A., Cikara, M. y Willer, R. (2020). Using social and behavioural science to support COVID-19 pandemic response. Nature Human Behaviour, 4. https://doi.org/10.1038/s41562-0200884-z

Bell, C. y Lewis, M. (2011). Economic implications of epidemics old and new. SSRN Electronic Journal, 54. https://doi.org/10.2139/ssrn.997387

Benjamin, S., Dillette, A. y Alderman, D. H. (2020). "We can't return to normal”: committing to tourism equity in the post-pandemic age. Tourism Geographies, O(0), 1-8. https://doi.org/10.1080/14616688.2020.1759130

Cejudo, D. J. (2020). Entre políticos y científicos. La Influenza A (H1N1) en México, 2009. En H. Casanova (Ed.), Educación y pandemia. Una visión académica. Universidad Nacional Autónoma de México. http://bitly.ws/9HKM

Centro Nacional de Programas Preventivos y Control de Enfermedades (Cenaprece). (2012). Plan nacional para la preparación y respuesta ante la intensificación de la influenza estacional o ante una pandemia de influenza. Secretaría de Salud. http://bitly.ws/9HKP 
Clyde, M. (2020) BAS: Bayesian variable selection and model averaging using Bayesian Adaptive Sampling. R package version 1.5.5

Consejo Nacional de Población (Conapo). (2018). Bases de datos de proyecciones de la población de México y de las entidades federativas, 2016-2050. Consultada el 19 de mayo de 2020. https://bit.ly/33e35mP

Diario Oficial de la Federación de México (2020, 14 mayo). Acuerdo por el que se establece una estrategia para la reapertura de las actividades sociales, educativas y económicas, así como un sistema de semáforo por regiones para evaluar semanalmente el riesgo epidemiológico relacionado con la reapertura de actividades cada entidad federativa, así como se establecen acciones extraordinarias. Secretaría de Salud. http://bitly.ws/9HKS

Driver, C. R., Valway, S. E., Onorato, I. M., Castro, K. G. y Morgan, W. M. (1994). Transmission of mycobacterium tuberculosis associated with air travel. JAMA: The Journal of the American Medical Association, 272(13), 1031-1035. https://doi. org/10.1001/jama.1994.03520130069035

Epstein, J. M., Goedecke, D. M., Yu, F., Morris, R. J., Wagener, D. K. y Bobashev, G. V. (2007). Controlling pandemic flu: the value of international air travel restrictions. PLOS ONE, 2(5). https://doi.org/10.1371/journal.pone.0000401

George, A. y Richards, D. (2012). Tourism in Trinidad and Tobago: the evolving attitudes and behaviors and its implications in an era of HIV/AIDS. Études Caribéennes, 19, 0-14. https://doi.org/10.4000/etudescaribeennes.5314

Gibbons, J. M., Cox, G. M., Wood, A. T. A., Craigon, J., Ramsden, S. J., Tarsitano, D. y Crout, N. M. J. (2008). Applying Bayesian model averaging to mechanistic models: an example and comparison of methods. Environmental Modelling and Software, 23(8), 973-985. https://doi.org/10.1016/j.envsoft.2007.11.008

Grais, R. F., Ellis, J. H. y Glass, G. E. (2003). Assessing the impact of airline travel on the geographic spread of pandemic influenza. European Journal of Epidemiology, 18(11), 1065-1072. https://doi.org/10.1023/A:1026140019146

Gössling, S., Scott, D. y Hall, C. M. (2020). Pandemics, tourism and global change: a rapid assessment of COVID-19. Journal of Sustainable Tourism, 0(0), 1-20. https://doi.org/10.1080/09669582.2020.1758708

Instituto Nacional de Estadística y Geografía (INEGI). (2015). Encuesta Intercensal 2015. Consultada el 19 de mayo de 2020. http://bitly.ws/9C8G 
Kuo, H. I., Chen, C. C., Tseng, W. C., Ju, L. F. y Huang, B. W. (2008). Assessing impacts of SARS and Avian Flu on international tourism demand to Asia. Tourism Management, 29(5), 917-928. https://doi.org/10.1016/j.tourman.2007.10.006

López-Gatell, H. (2020, 12 de marzo). Conferencia de prensa de la Secretaría de Salud.

Lu, R., Zhao, X., Li, J., Niu, P., Yang, B., Wu, H., Tan, W. (2020). Genomic characterization and epidemiology of 2019 novel coronavirus: implications for virus origins and receptor binding. The Lancet, 395(10224), 565-574. https://doi. org/10.1016/S0140-6736(20)30251-8

Mao, C. K., Ding, C. G. y Lee, H. Y. (2010). Post-SARS tourist arrival recovery patterns: an analysis based on a catastrophe theory. Tourism Management, 31(6), 855-861. https://doi.org/10.1016/j.tourman.2009.09.003

Oehmichen-Bazán, C. y París Pombo, M. (2010). El miedo ante el riesgo global: apuntes sobre la emergencia del virus $\mathrm{A} / \mathrm{H} 1 \mathrm{~N} 1$ y el turismo. Revista Nuevas Tendencias en Antropología, 1, 161-185. https://bit.ly/2RcGyBk

Organización Mundial de la Salud (OMS). (2009). Preparación y respuesta ante una pandemia de influenza. Documento de orientación de la OMS. http://bitly. ws/9LvE

Organización Mundial de la Salud (OMS). (2020). Brote de enfermedad por coronavirus (COVID-19). http://bitly.ws/9HKI

Organización Mundial del Turismo (OMT). (2009). Travel and tourism under pandemic conditions. Review and preparation exercise. https://doi. org/10.18111/9789284413317

Orozco-Núñez, E., Alcalde-Rabanal, J. E., Ruiz-Larios, J. A., Sucilla-Pérez, H. y García-Cerde, R. (2015). Mapeo político de la discriminación y homofobia asociadas con la epidemia de VIH en México TT - Discrimination and homophobia associated to the human immunodeficiency virus epidemic. Salud Pública de México, 57(3), s190-s196.

Paraskevis, D., Kostaki, E. G., Magiorkinis, G., Panayiotakopoulos, G., Sourvinos, G. y Tsiodras, S. (2020). Full-genome evolutionary analysis of the novel corona virus (2019-nCoV) rejects the hypothesis of emergence as a result of a recent recombination event. Infection, Genetics and Evolution, 79, 104212. https:// doi.org/10.1016/j.meegid.2020.104212 
R Core Team (2020). R: a language and environment for statistical computing. $R$ Foundation for Statistical Computing. https://www.R-project.org/.

Raftery, A. E. (1995). Bayesian model selection in social research. Sociological Methodology, 25(1), 111-163. https://doi.org/10.2307/271063

Rassy, D. y Smith, R. D. (2013). The economic impact of H1N1 on Mexico's tourist and pork sectors. Health Economics, 22(7), 824-834. https://doi.org/10.1002/ hec. 2862

Remuzzi, A. y Remuzzi, G. (2020). COVID-19 and Italy: what next? The Lancet, 395(10231), 1225-1228. https://doi.org/10.1016/S0140-6736(20)30627-9

Ridenhour, B., Kowalik, J. M. y Shay, D. K. (2018). Unraveling R 0: considerations for public health applications. American Journal of Public Health, 108(S6), S445S454. https://doi.org/10.2105/AJPH.2013.301704r

Scrucca, L., Fop, M., Murphy, T. B. y Raftery, A. E. (2016). Mclust 5: clustering, classification and density estimation using Gaussian finite mixture models. The $R$ Journal, 8(1), 289-317. https://bit.ly/3ifPYHS

Secretaría de Salud. (2020). Datos abiertos de México - Información referente a casos COVID-19 en México. https://bit.ly/2R9Rn6V

Secretaría de Turismo (Sectur). (2019). Pueblos Mágicos de México. http://bitly.ws/9LvM

Secretaría de Turismo (Sectur). (2020). Datatur3 - Actividad Hotelera. http://bitly. ws/9Lwh

Teitler-Regev, S., Shahrabani, S. y Goziker, O. (2013). The effect of economic crises, epidemics and terrorism on tourism. International Journal of Business \& Economics, 5(2), 19-32.

Wasserman, L. (2000). Bayesian model selection and model averaging. Journal of Mathematical Psychology, 44(1), 92-107. https://doi.org/10.1006/ jmps.1999.1278

Wilson, M. E. (1995). Travel and the emergence of infectious diseases. Emerging Infectious Diseases, 1(2), 39-46. http://bitly.ws/9Lwe

Wilson, M. E. (2020). What goes on board aircraft? Passengers include Aedes, Anopheles, 2019-nCoV, dengue, Salmonella, Zika et al. Travel Medicine and Infectious Disease, 33, 101572. https://doi.org/10.1016/j.tmaid.2020.101572 
Yang, Y., Zhang, H. y Chen, X. (2020). Coronavirus pandemic and tourism: dynamic stochastic general equilibrium modeling of infectious disease outbreak. Annals of Tourism Research. https://doi.org/10.1016/j.annals.2020.102913

Zhang, T., Wu, Q. y Zhang, Z. (2020). Probable pangolin origin of SARS-CoV-2 associated with the COVID-19 outbreak. Current Biology, 30(7), 1346-1351. https://doi.org/10.1016/j.cub.2020.03.022 